\title{
WestVirginiaUniversity
}

THE RESEARCH REPOSITORY @ WVU

Graduate Theses, Dissertations, and Problem Reports

2005

\section{Instant message communication and its impact upon written language}

Lara L. Eller

West Virginia University

Follow this and additional works at: https://researchrepository.wvu.edu/etd

\section{Recommended Citation}

Eller, Lara L., "Instant message communication and its impact upon written language" (2005). Graduate Theses, Dissertations, and Problem Reports. 1591.

https://researchrepository.wvu.edu/etd/1591

This Thesis is protected by copyright and/or related rights. It has been brought to you by the The Research Repository @ WVU with permission from the rights-holder(s). You are free to use this Thesis in any way that is permitted by the copyright and related rights legislation that applies to your use. For other uses you must obtain permission from the rights-holder(s) directly, unless additional rights are indicated by a Creative Commons license in the record and/ or on the work itself. This Thesis has been accepted for inclusion in WVU Graduate Theses, Dissertations, and Problem Reports collection by an authorized administrator of The Research Repository @ WVU. For more information, please contact researchrepository@mail.wvu.edu. 


\title{
Instant Message Communication and its Impact upon Written Language
}

\author{
Lara L. Eller
}

\begin{abstract}
Thesis Submitted to the Perley Isaac Reed School of Journalism at West Virginia University in partial fulfillment of the requirements for the degree of
\end{abstract}

Master of Science in Journalism

Terry L. Wimmer, Ph.D., Chair Brian R. Patterson, Ph.D.

R. Ivan Pinnell, Ph.D. Associate Professor Pamela D. Yagle

Journalism Department

Morgantown, West Virginia 2005

Keywords: Instant Messaging, Technological Determinism, Language Deconstruction 


\section{Abstract \\ Instant Message Communication and its Impact upon Written Language}

\section{Lara L. Eller}

The purpose of this study is to explore the effects of computer-mediated communication upon users. The theory of technological determinism will be defined, discussed in detail, and applied to the research of computerized communication. The concept of language deconstruction (i.e., Internet slang, use of emoticons, and shorthand) in instant messaging will be analyzed through content analysis and through a series of interviews with high school and college journalism instructors. Does computer-mediated communication, specifically Instant messaging have a positive or negative effect on written language? The author discovered that many instant message conversations, in personal and professional settings, have Internet slang and shorthand. The interviews revealed that many high school instructors have seen Internet language in their students' written work. College professors did not see as much shorthand, but were concerned about the effects of computers related to editing and plagiarism. 


\section{Table of Contents}

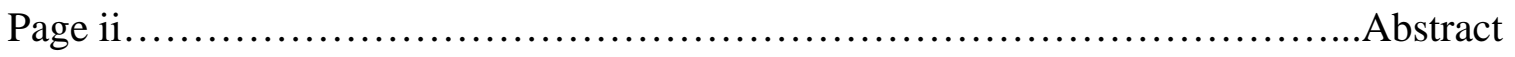

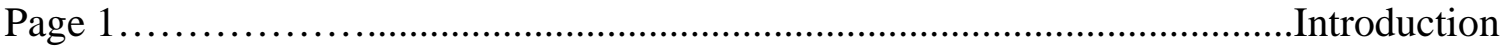

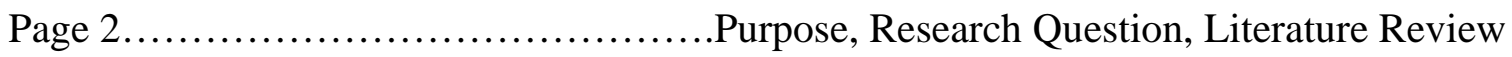

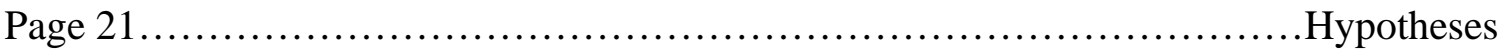

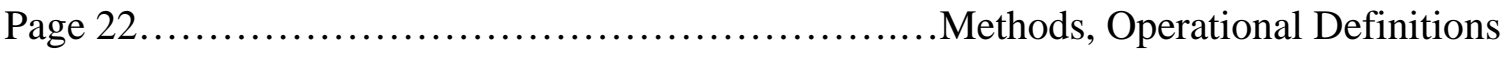

Page 24..................Table 1.1: Variable Breakdown for Coding Content Analysis

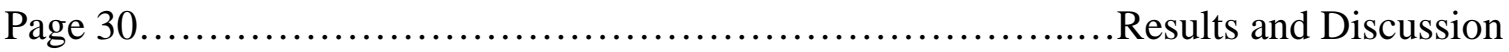

Page 30..................... Table 1.2: Numeric Results of Professional Conversations

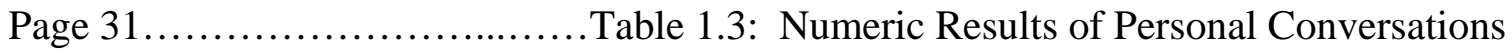

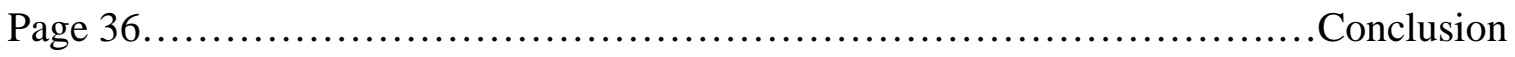

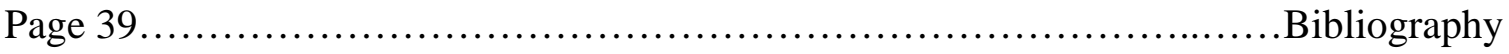

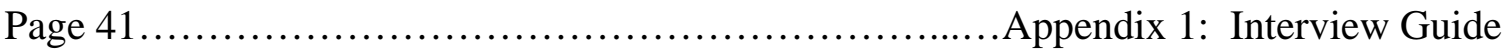

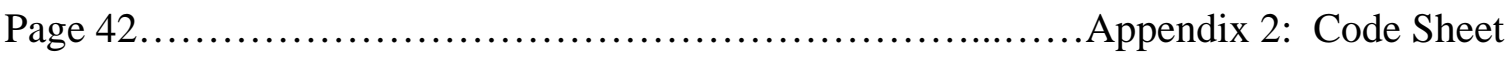

Page $44 \ldots \ldots \ldots \ldots \ldots \ldots \ldots \ldots \ldots \ldots \ldots \ldots \ldots \ldots \ldots$ Appendix 3: Sample High School Interview

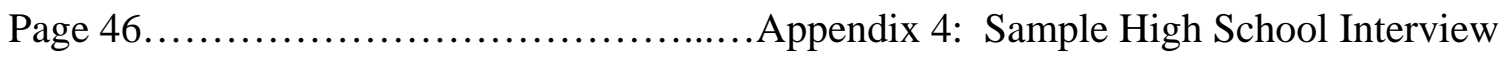

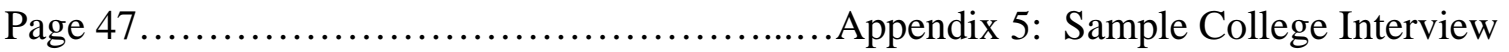

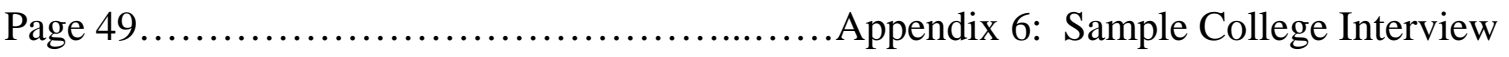




\section{Introduction}

Examining the relationship between society and technological advancements such as the Internet is important. More specifically, how do individuals react to computermediated communication? Some people think computer-human interaction is dehumanizing while others discount it completely and claim it is utterly impossible. The reality is that computer-human communication is almost essential in everyday life to keep up with the ever-growing varieties of technology. ${ }^{1}$ In the "Information Society" humanmachine interaction is becoming routine --if not a natural way of life for a lot of people. ${ }^{2}$

Nonverbal communication is significantly different from computer-mediated communication. For example, face-to-face exchanges typically consist of verbalized responses grouped with nonverbal cues such as facial expressions, body language, and gestures. In contrast, computer-mediated communication eliminates all three nonverbal reactions. Without nonverbal cues, computer-mediated communication systems are “dramatically different” from face-to-face interaction. ${ }^{3}$

Four specific variables create a contrast between face-to-face and computermediated systems: "the channels used, the type of discursive modes used in each system, the different kinds of social roles involved in each system, and the use of time embedded in each system.”4 These four variables, along with other societal and technological

\footnotetext{
${ }^{1}$ James W. Chesebro and Donald G. Bonsall, Computer-Mediated Communication: Human Relationships in a Computerized World (Tuscaloosa: The University of Alabama Press, 1979), 63.

${ }^{2}$ Ibid.

${ }^{3}$ Ibid., 58.

${ }^{4}$ Ibid.
} 
elements, help to reveal the advantages and disadvantages of computer-mediated communication in society.

\section{Purpose}

Once the variables of face-to-face interaction and of computer-mediated communication are apparent, this writer will identify the types of communication used in society (with emphasis on the computer-mediated), their effects upon society, and the preferred methods of computer-mediated communication. Computerized communication will emphasize Internet communication with an accent upon instant messaging. Language deconstruction and social development are key factors in studying Internet communication in relation to society.

\section{Research Question}

Does computer-mediated communication, specifically Instant messaging, have a positive or negative effect upon written language?

\section{Literature Review}

This literature review will provide a better understanding of computerized communication types and their effects upon society. Analyzing prior researchers' findings will aid in contrasting interpersonal and computer-driven interaction. This author also will present the theory behind the development of computer-mediated communication. Specific definitions and contrasts assist in building a foundation for the debate between the advancements of Internet communication in society and the effects such innovations have on their participants. Is society too dependent upon Internet communication? What are the social and intellectual effects upon its users? These are questions the researcher will explore in the literature review. 
To better understand the Internet's use in society, one should discuss and apply the theory of technological determinism. This fairly new theory has become more popular with the Internet's frequent use and success. A basic definition of technological determinism is "simply that all change in society occurs as a result of interactions with the technology of that society." According to this philosophy, all societal change is due to technological advancements.

This is a bold statement in that it has a direct opposite called "social determinism.” Social determinism argues that free will is the underlying cause of social advancement, and a technological advance is merely a result of that will. ${ }^{6}$ But technological determinists have two different perspectives to discount the social determinists. First, many technology scholars believe that innovations in technology are autonomous and, thus, not influenced by society. Secondly, researchers have also said that previous accomplishments have "set the pace" for developing technology, which makes individuals' demands for new technologies a product of their interactions with the systems of the past. The relationship is, therefore, a cyclical effect of the demand. ${ }^{7}$

A concrete media example that favors technological determinism over social determinism is the invention of the printing press. Mechanical and computer advancements since then have changed society as a whole. Online, as well as printed, newspapers and magazines would not be circulated nearly as much as they are now without the creation of the printing press and computers. These devices were obviously

\footnotetext{
${ }^{5}$ http://www.cartoon.ecn.purdue.edu/ birkhaus/H515pt1a.html. Accessed: September 30, 2003.

${ }^{6}$ Ibid.

${ }^{7}$ Ibid.
} 
influenced by a previous technology such as simple pen and paper composition. ${ }^{8}$

Advancements like the printing press and computers will continue society's evolution. Before these machines the news was spread mostly by face-to-face interaction, which was at risk of allowing personal bias in and leaving pertinent details out. ${ }^{9}$

Marshall McLuhan, a media communications expert, advocated technological determinism and defined it by dividing "human history" into four separate but related categories. These subdivisions, which this author will explain further, are the tribal age, the literate age, the printed age, and the electronic age. The categories are marked by technological advancements of each time period and their accompanying social changes. ${ }^{10}$ Research explained by McLuhan is in favor of technological determinism rather than social determinism.

McLuhan states that the invention of mass media tools such as the printing press and advertising campaigns characterized the print age. These new forms of mass media influenced social change, however, "free will” which social determinism advocates, was not the result. ${ }^{11}$

The beginning of the electronic age was marked by the development of a TransAtlantic telegraph cable. Because of McLuahn's research and examinations of the media an online article entitled "Marshall McLuhan: 'The Medium is the Message”" stated he "is considered by many to be the first father and leading prophet of the electronic age."12

\footnotetext{
${ }^{8}$ Ibid., 2.

${ }^{9}$ Ibid.

${ }^{10}$ Ibid., 1.

${ }^{11}$ Ibid., 2.

${ }^{12}$ www.leaderu.com/orgs/probe/docs/mcluhan.html. Accessed: May 2005.
} 
In McLuhan’s studies, the electronic age suggested the rise of a “Global Village.” Now, the Internet allows people to communicate despite the miles between them. In other words, the technology is able to influence social change across the world and technological determinism is supported over social determinism because free will is not involved in the change that society undergoes. ${ }^{13}$

Technological determinism has led to several studies being conducted about the lack of Internet service in foreign countries. Researchers wanted to know how people would use the Internet if given the opportunity. In 1999 the municipal government of New Delhi teamed up with another company in India called the National Institute of Information Technology. The two entities conducted one of the first experiments to give computer access to the city’s most impoverished areas. Naturally, the researchers eventually discovered some unexpected variables. After nine months, the children learned how to manipulate the computers’ joysticks and buttons. However, no educational programs at the kiosks stimulated the children so they used the computers to play games. As a result, some parents complained about the machines. One parent said that her son had done well in school in the past, but he began to spend all his free time at the computer station and his schoolwork was suffering. The experiment had failed in some respects such as educational stimulation but the researchers realized that minimally invasive education was minimally effective communication. ${ }^{14}$

Another experiment was conducted in India in 2000. This time researchers provided computer training to villagers for a nominal fee. Computer managers also

\footnotetext{
${ }^{13}$ http://www.cartoon.ecn.purdue.edu/ birkhaus/H515pt1a.html. Accessed: September 30, 2003.

${ }^{14}$ Mark Warschauer, “Demystifying the Digital Divide,” Scientific American, August 2003, 2.
} 
helped to manipulate the programs for the illiterate. After nine months, in October 2001, the computer stations in India had accumulated 21,300 users, of which 80 percent had an annual income of less than $\$ 300$. Proportionately, compared to the village’s population, the number of users was a small percent. Another factor integrated in the latter study but not included in the 1999 study was useful software, which would benefit users intellectually and financially. Software gave villagers input about how to manage a local government, how to find weather reports and other information that could assist them in planting their crops for the current season. ${ }^{15}$

The goals of bringing technology to depressed areas are basically for education and social inclusion. Ideally, technology should be integrated into societal systems and processes. Therefore, the purpose of introducing technologies such as computers is not just to overcome the "digital divide,"16 but also to bridge the gap of socially excluded populations. ${ }^{17}$

Technological determinism is closely related to other theories: namely the knowledge gap ${ }^{18}$, the spiral of silence ${ }^{19}$, and users and gratifications ${ }^{20}$. Accessibility is

\footnotetext{
${ }^{15}$ Ibid., 2-3.

${ }^{16}$ Ibid., 1 . The term digital divide means the split between peoples with Internet access and computers, and those without.

${ }^{17}$ Ibid., 3-4.

${ }^{18}$ The Knowledge gap model shows the difference between a society's better-informed and less informed segments (http.//www.arapaho.nsuok.edu/\%7Evinevard/Research/Mass_Culture_Theories.htm. Accessed: October 21, 2003).

${ }^{19}$ Ibid. The spiral of silence theory is the idea that people holding views contrary to the more dominant ones are moved to keep their views silent for fear of rejection.

20 Shearon A. Lowery and Melvin L. DeFleur, Milestones in Mass Communication Research: Media Effects (New York: Longman Publishers USA, 1995), 107. Users and Gratifications theory examines the nature of the satisfaction of the audience. Three major uses come from Users and Gratifications theory:
} 
important in all three of these theories as it is in technological determinism, which is similar to the knowledge gap theory in that technological determinism widens the gap between cultures that are connected and cultures that are not. The spiral of silence theory is similar in that some minorities are silent because they are not able to communicate with the population at large (i.e., they do not have the opportunities to make their opinions known as the technologically inclined do). Finally, the users and gratifications theory is similar because it is largely based upon Internet use in society.

Accessibility is problematic in relation to technological determinism. In a late 2001 study conducted by the Benton Foundation, which promotes public uses of communications technology, 80 percent of American families with an annual income greater than $\$ 75,000$ were online compared to the 25 percent of poorer families who were connected. Total Internet access was 55 percent white; 31 percent, African-American; and 32 percent, Hispanic. On an international level, in African countries, less than 1 percent of the population is online. ${ }^{21}$

One must recognize that advancements such as video cameras, the Internet, email, and the World Wide Web have reflected good and bad influences when utilized in research. Today's technology “has made conducting, processing, analyzing, and reporting research much easier, cheaper, and faster." ${ }^{, 22}$ Most importantly, it has helped emotional release, wishful thinking, and valuable advice. These qualities are for the user to reap in handling their own lives.

${ }^{21}$ Mark Warschauer, Scientific American, 1.

${ }^{22}$ Paula M. Poindexter and Maxwell E. McCombs, Research in Mass Communication: A Practical Guide (Boston: Bedford/St. Martin’s, 2000), 369. 
make studies more reliable and valid. With the invention of statistical software and Webbased surveys, researchers save time and money. ${ }^{23}$

Unfortunately these advancements have contributed to the proliferation of research with questionable validity. Although computers, telephones and other communication tools have made it easy for individuals and groups to conduct informal surveys, devices such as answering machines and caller IDs have created barriers for response rates. These machines used to screen calls sometimes block researchers conducting phone surveys. ${ }^{24}$

Computerized interviewers also have aggravated test subjects into not wanting to reply before the interview begun. Listening to a computer-generated voice can agitate anyone; as if a respondent stays on the phone long enough to complete an interview, animosity toward the interviewing tool may affect his or her answers. ${ }^{25}$

The technological determinism theory can be efficient in research because societal changes may be attributable to technological advancements. This bold theory poses quite a threat to the pure social determinists, who believe that free will of society controls technological progress. A social determinist would not even consider that advancement could control him or her. Innovations discussed in this literature review focus upon computer-mediated communication.

Interpersonal communication is a key term in the discussion of differing communication types. The first step to effectively contrast dissimilar types such as face-

\footnotetext{
${ }^{23}$ Ibid.

${ }^{24}$ Ibid.

${ }^{25}$ Ibid.
} 
to-face and Internet communication is to properly define "interpersonal communication." The best definition is "face-to-face communication in which each person influences what is being said by the other person.”26 Therefore, face-to-face interaction (interpersonal communication) and computerized communication have four specific differences. ${ }^{27}$

The first variable of difference is the channel. In face-to-face interaction both verbal and nonverbal channels are occupied. Researcher A. Mehrabian claims that 93 percent of meanings conveyed in face-to-face channels are nonverbal. ${ }^{28}$ In computerized communication, the nonverbal channel is usually obliterated. All meanings must pass through the verbal channel. However, computer users have attempted to account for some of the lost nonverbal communication and are attaching "nonverbal facial reactions" through the use of symbols. ${ }^{29}$ For example, a colon with an end parenthesis [ن] can indicate the person is happy or something is funny because the combined punctuation marks look like a smiley face. Some computer software is, in fact, programmed to recognize the combination; once the buttons are pressed together they turn the oncesideways smiley into an upright, more attractive smiley face like the one shown above. This is one of many emoticons used in computer-mediated communication systems, especially instant messaging. Such symbols help to substitute for some missing nonverbal communication that exists in face-to-face interaction. And, if nothing else,

\footnotetext{
${ }^{26}$ This is one of eight definitions used in this text to describe interpersonal communication because many sources give separate definitions that apply to the current aspect of the subject being examined. Mark V. Redmond, Interpersonal Communication: Reading in Theory and Research (Fort Worth: Harcourt Brace College Publishers, 1995), 4.

${ }^{27}$ Chesebro and Bonsall, Computer-Mediated Communication, 58.

${ }^{28}$ Ibid., 58-59; A. Mehrabian, Silent Messages: Implicit Communication of Emotions and Attitudes (Belmont: Wadsworth, 1981).

${ }^{29}$ Ibid.
} 
they convey a sense of personality to the conversation and provide a novelty for online communicators. ${ }^{30}$ On the downside, this symbolic system "does not reveal the unique, personal, and spontaneous nonverbal reactions. ${ }^{\text {31 }}$ Therefore, researchers claim all exchanges in computer-driven interactivity are solely verbal. ${ }^{32}$

The next variable is the discursive mode. In face-to-face interaction verbal responses are oral. Subtle hints that pass through the communicators' voice quality, pitch, tone, and volume are just as important as the actual conversation's content. Of course, in computerized conversation, verbal exchange exists only in 'written' form. A person submits content line by line with no sound cues. However, the more competent a writer is the more satisfied and confident he or she will be in a computerized setting. ${ }^{33}$ This statement alludes to the fact that a user must know how to manipulate the language first so he or she can convey a message properly without the oral element advantage of interpersonal communication. Additionally, shorthand and symbols in a computerized conversation provide efficiency and timeliness but do not relate to the incompetence in speech of the user. However, like many other trends, when used excessively bad habits are difficult to dismiss, and online communicators run the risk of being language brutalizers if deconstruction continues outside the digital realm.

The third variable of contrast is feedback. This element is fairly simple. In interpersonal face-to-face interaction, feedback is constant. Verbal or nonverbal feedback keeps the conversation flow smooth. A simple head nod or "uh huh”-like

\footnotetext{
${ }^{30}$ Patricia Wallace, The Psychology of the Internet (Cambridge: Cambridge University Press, 1999), 18.

${ }^{31}$ Ibid.

${ }^{32}$ Chesebro and Bonsall, Computer-Mediated Communication, 59.

${ }^{33}$ Ibid.
} 
response can show that someone is actively listening. Thus, the conversation continues. Again computer-mediated interaction feedback is different. For example, in instant messaging to signal that someone is finished with a thought or idea, he or she hits the enter key and sends a message. Additionally, most users typically send feedback during a conversation in the form of something like "oic," which is an abbreviated version of the response “Oh, I see!” This is, of course, different from face-to-face communicating because the feedback is not happening right in front of the communicator and, if someone is listening, the response will be immediate. With online talkers the feedback step takes a little longer; and it is tough to tell if a person is really following a conversation without making eye contact. Online communicating is more of a one-way transmission. ${ }^{34}$ However, online communication still carries some of the same qualities as a two-way transmission. Although a response may take longer online, the conversation itself still occurs in real time, just as a face-to-face transmission does.

The variable of "social roles of the participants" is interesting because it focuses on human behavior rather than upon abilities and the aspects of face-to-face communication vs. computer-mediated communication. During a face-to-face exchange communicators must expose a "sociological composite of the self." Therefore, a person’s age, race, gender, etc. will be obvious immediately in a face-to-face interaction. On the other hand, these elements of the self may remain private during a computer-generated conversation because communicators cannot see each other. ${ }^{35}$ Anonymity may help to eliminate judgments, stereotyping, and prejudices that may otherwise occur during a face-to-face encounter. Elements of the self are revealed at the communicator's

\footnotetext{
${ }^{34}$ Ibid., 60-61.

${ }^{35}$ Ibid.
} 
discretion; whatever he or she wants the receiver to know, they can tell; if not, the sender may withhold the information.

The fourth and final variable of contrast is the use of time. Interpersonal communication always occurs in real time, which reflects the present, or what is happening now. Some elements, such as pauses and tone, in a face-to-face encounter may convey a certain meaning for a conversation. People may associate a pause with indecisiveness, poor-listening, or even dishonesty. During a face-to-face conversation, “every moment counts, and every moment has a particular quality that affects the social relationship.”36 Time is difficult to grasp in computer-mediated communication because some of it occurs in real time and some does not. Email is much like a letter; it does not occur in real time and is less conversational than chat rooms and instant messaging, which do occur in real time. The effects of these computer-generated communications are not much different from that of a face-to-face exchange. Only minor distinctions exist between the two in the time category, which is what sets them apart in every other way, save the sociological variable:

Face-to-face message constructions are characterized by a complex, spontaneous, simultaneous, and immediate collage of verbal, nonverbal and oral symbols. In contrast, computer-mediated message constructions are characterized by written, deliberate, and delayed symbols. ${ }^{37}$

It is significant to discuss different forms of computer-mediated communication and the effects they have on our technology-driven society. The types of Internet communication to be considered briefly are email, discussion boards/bulletin boards, and chat. This writer will spotlight the newest form of virtual communication, instant

\footnotetext{
${ }^{36}$ Ibid.

${ }^{37}$ Ibid., 61.
} 
messaging, in more detail than the latter three. The elements of communication have two major differences that separate them-- time and the number of recipients. Although, these are not the only distinctions between the modes, they are the most significant. For example, email does not occur in real time while chat and instant messaging do. Communication between receivers may include “one-to-one, one-to-many, and many-tomany."38 Internet use usually starts with email and then progresses to chatting, interactive discussion groups and instant messaging. Soon after, small communities form all over the Web; and groups of people that may not otherwise meet each other, get connected. $^{39}$

Electronic mail (email) was one of the first modes of Internet communication. It is also one of the least controversial methods of online communication because it is closely related to letter writing, which has been around for centuries. It is used to keep in touch with family and friends. Email is also beneficial for government agencies and businesses. It has become a staple for Internet users "who now consider it to be side by side with the Web as indispensable technology." ${ }^{40}$ An entertaining list of email addiction symptoms circulated a few years ago contained statements such as: You know you are addicted to the Internet when you get up in the middle of the night for a glass of water and you check your email before you go back to bed. ${ }^{41}$ However, two modes of online communication that make email appear almost archaic, are instant messaging and chat.

\footnotetext{
${ }^{38}$ Steven G. Jones, ed. Virtual Culture: Identity and Communication in Cybersociety (London: Sage Publications, 1997), 50.

${ }^{39}$ Ibid., 139.

${ }^{40}$ Wallace, The Psychology of the Internet, 5.

${ }^{41}$ Ibid.
} 
The most notable difference between instant messaging and chat versus email is that the first two occur in real time. However, email has a special feature that can send a message to one person or to an entire address book. ${ }^{42}$ Although email is one of the oldest forms of virtual communication, many online communicators still use it. In 1997 America Online was carrying more than 13 million e-mail messages on a daily basis. ${ }^{43}$

Discussion groups and bulletin boards are similar because many participants read and respond to both. ${ }^{44}$ Discussion groups provide a helpful tool to meet people. For example, a group of gay men who were tired of trying to meet people in bars formed a group with other men with the same problem. ${ }^{45}$ Their discussion group formed with a positive outcome in mind. Unfortunately, the results of such a service do not always coincide with the intentions. Other Web-based discussion groups have formed to promote white supremacy and religious persecution. ${ }^{46}$ Some bulletin boards have mottos plastered on them to send ideas like "Keeping America, White, Straight, and Proud!"47 Although “cyber hate” is common on the Web, countless self-help groups and comfort discussion groups communicate as well. The Internet is an ideal setting in such units because they preserve anonymity and are "disinhibiting." Therefore, if one member does not want another member to know who he or she is, one or both can hide behind a screen

\footnotetext{
${ }^{42}$ Ibid., 35.

${ }^{43}$ Jeffery S. McQuillen, “The Influence of Technology on the Initiation of Interpersonal Relationships," Education 123 (Spring 2003): 616.

${ }^{44}$ Jayne Gackenbach, ed., Psychology and the Internet: Intrapersonal, Interpersonal, and Transpersonal Implications (San Diego: Academic Press, 1998), 201.

${ }^{45}$ Jones, Virtual Culture, 138.

${ }^{46}$ Ibid., 193.

${ }^{47}$ Ibid.
} 
name. The term "disinhibition" is a relief for participants because they can say anything they are feeling and not worry if other members will criticize him or her. People also do not have to be concerned with oral ridicule. Group members hardly meet each other. ${ }^{48}$ Although discussion groups and bulletin boards are similar to chat rooms, most of the former two categories do not occur in real time.

Chatting is "the next best thing" to instant messaging. Some users prefer chatting because they want to search for new online communities and because topical chat rooms are easy to find with search engines and personalized Web pages. "Individuals united by common goals and interests” can get together in specific Web spaces to communicate thanks to chat rooms. ${ }^{49}$ However, with chat rooms some safety precautions are vital with children. ${ }^{50}$ Recent studies show that face-to-face meetings between chatting partners have been fairly harmless overall. Only one percent said that meeting an online friend was a bad experience and made them uncomfortable. An astonishing 0 percent reported that youths were physically or sexually assaulted by an online friend. ${ }^{51}$

Again, chatting is closely related to instant messaging because it occurs in real time. However, most chat rooms are on a one-to-many and even many-to-many basis, whereas most instant messaging services focus on the one-to-one interaction.

The final and one of the most talked about forms of Internet communication is that of instant messaging (IM). Most, if not all research that is done on instant messaging

\footnotetext{
${ }^{48}$ Gackenbach, Psychology and the Internet, 129.

${ }^{49}$ Jones, Virtual Culture, 146.

${ }^{50}$ Gackenbach, Psychology and the Internet, 99.

${ }^{51}$ Janis Wolak, Kimberly Mitchell, and David Finklhor, “Close Online Relationships in a National Sample of Adolescents," Adolescence 37 (Fall 2002): 10.
} 
is largely exploratory because a lot of necessary information has not yet been examined due to the fact that the technology is rapidly evolving. ${ }^{52}$

When comparing instant messaging to other modes of off and on-line communication, the term of interpersonal communication must be reconstructed. While using Internet communication forms, the interpersonal focus is on the psychological composition of an individual, rather than the sociological or cultural make-up of the receiver. ${ }^{53}$ For example a sender's stereotype of a certain culture, could influence the way they communicate with another person.

The definition previously used dealt with face-to-face exchanges and the influences of each communicator in a personal setting. ${ }^{54}$ When discussing Internet forms such as instant messaging, literal face-to-face exchange is not included. However, most instant messages are traded by individuals who know each other outside of the virtual world so they may already know the individual's social and cultural convictions. One-toone versus one-to-many is a major existing difference between IM and chat. For example a private exchange between two individuals at a dinner party is an equal comparison to instant messaging, whereas a dinner conversation involving all members in attendance is closer related to chat rooms. Chat rooms are usually forums for communicators who have never officially met to log on and get to know each other without actually seeing each other. Again the major difference that separates these two modes is that in chat rooms the exchange can be one-to-one or one-to-many. The preferred exchange is one-

\footnotetext{
${ }^{52}$ Amitai Etzioni and Oren Etzioni, "Face to Face and Computer Mediated Communities: A Comparative Analysis,” Information Society 15 (Oct-Dec 1999): 241.

${ }^{53}$ McQuillen, Education, 619.

${ }^{54}$ Redmond, Interpersonal Communication, 4.
} 
to-one in instant messaging, although with the advances of some services in instant messaging, the user can build a chat room and talk to more than one person at a time. A deciding factor in this scenario is that the respondent can either accept or reject the chat room invitation to group chat.

Instant messaging has become so popular that users not only log-on at home, but at school and at the office. A new Education Department reported 99 percent Internet access in public schools, whether in city or rural locations, in 2002. This is a rapid increase from the 35 percent reported eight years ago. ${ }^{55}$ Instant messaging has been utilized in the workplace. Some corporations have accepted IM technology because it enables co-workers to communicate quickly and cheaply. The problem is that workrelated matters are not being discussed. ${ }^{56}$ For example, out of a 204 sample in the United Kingdom, 65 percent reported using IM for personal purposes such as flirting and gossip during business hours. Half of the respondents admitted to using coarse language; 40 percent used it to talk about colleagues during conference calls and nearly one third said they had used IM for making a sexual proposition on another co-worker. The statistics from U.S. respondents were milder. Less than one in five Americans said they used IM to gossip about other co-workers or to flirt. ${ }^{57}$

It is important to recognize that the most users of IM come from the younger generation. John Bailey, an overseer of educational technology said, “Children are often the first adopters of a lot of technology. They grow up with it. They don't have to adapt

\footnotetext{
${ }^{55}$ http://www.cnn.com/2003/EDUCATION/10/29/students.computers.ap/index.html. Accessed: November 10, 2003.

${ }^{56}$ http://www.cnn.com/2003/TECH/internet/09/16/using.IM.reut/index.html. Accessed: September 16, 2003.

${ }^{57}$ Ibid.
} 
to it... Students, by and large, are dominating the Internet population.” ${ }^{\text {„58 }}$ Sixty percent of 10 year olds use the Internet and 80 percent of 16 year olds use it. More than half use the Internet for IM and other forms of computer-mediated communication. ${ }^{59}$

As previously stated, exploratory research is the only literature to study when examining the aspects of IM. There is no way to determine the long term effects it has on adolescents until they are adults. However, researchers are concerned with the effects of IM on today’s youth.

The researchers in agreement of frequent IM use say that technologies such as instant messaging help the distance between cultures and countries to shrink, making interpersonal interaction increase. The end result is supposed to be a better connection to the "Global Village."60 These researchers validate the increased social isolation by stating that with the ease and the time-saving qualities of advanced technology, users have the opportunity to become less interdependent and more independent and selfreliant. $^{61}$

Another argument on the frequent use of IM side is that it is educational for international communicators. In a study of Australian adolescent users, two friends who were once geographically close got separated and kept in touch through IM. The

\footnotetext{
${ }^{58}$ http://www.cnn.com/2003/EDUCATION/10/29/students.computers.ap/index.html. Accessed: November 10, 2003.

${ }^{59}$ Ibid.

${ }^{60}$ McQuillen, Education, 617.

${ }^{61}$ Ibid.
} 
outcome of the change for the girls was awareness and sensitivity to other ways of life. ${ }^{62}$ The Australian article also supported IM by reporting that it helped build confidence within adolescent communicators. With the physical body out of sight, adolescents are able to observe, and engage in conversations with the opposite sex without being paranoid about their appearance. $^{63}$

On the opposing side are researchers that the author has termed "the purists." Their focus is on face-to-face exchange and its advantages over instant messaging. The most discussed aspect for the inferiority of Internet communication argues that on-line services do not have the nonverbal code that is present in face-to-face exchange. As a result, the limited nonverbal channel may not convey the proper message to the receiver. ${ }^{64}$ Without nonverbal cues, the messages may be seen as impersonal and debilitating to the conversational exchange. ${ }^{65}$

A separate concern, and perhaps the least studied concept in Instant message use is that of language deconstruction. The term language deconstruction in this content is the users of IM are developing a shorthand-type of dialogue when communicating. This shorthand enables the senders and receivers of instant messages to converse quickly so they can follow and participate in an arguably effective fashion. Two completely

\footnotetext{
${ }^{62}$ Cynthia Lewis and Bettina Fabos, "But Will it Work in the Heartland? A Response and Illustration," Journal of Adolescent and Adult Literacy 43 (February 2000): 464.

${ }^{63}$ Ibid., 466.

${ }^{64}$ McQuillen, Education, 618.

${ }^{65}$ Ibid.
} 
different opinions exist with this concept of language deconstruction. Some see this shorthand as a positive aspect because it encourages writing and thinking of its users. ${ }^{66}$

Of course the opposition states that all grammar rules are being ignored, and symbols are substituted for words and emotions by this arrival of language deconstruction. A recent article, cleverly entitled “Can U Rite?” reported that “the usual difficulties of teaching students to spell are aggravated by the error-strewn slangy

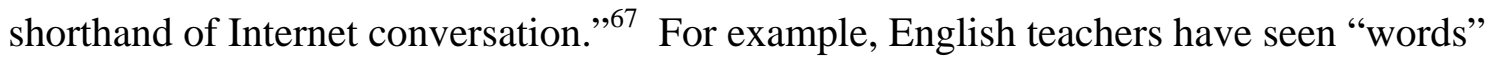
like u (you), r (are), b4 (before), and rite (right and write) and @ in student composition papers. ${ }^{68}$ Perhaps a more explicit example would be:

"B4 we have to perform ppl have to practice," an eighth-grade Indiana student wrote. When the teacher asked him to translate the sentence, student thought her out of touch. "You are so used to abbreviating" you do it in schoolwork, a 15-year-old New Jersey student explained. Teenage Internet language commonly uses abbreviations like oic (oh I see), nm (not much), jk (just kidding), brb (be right back), and ttyl (talk to ya later.) ${ }^{69}$

Therefore, supporters of Internet shorthand are pleased that users are manipulating and experimenting with writing and thinking. However, some people, namely educators, "see it in another sign of collapsing standards.,"70

Finally, with all the have-nots of IM in mind, some researchers agree that although the development of interpersonal effects may be slower, the depth of the relationship can be equal to the face-to-face counterpart. ${ }^{71}$

\footnotetext{
${ }^{66}$ Harold Orlans, “Can U Rite?,” Change (January/February 2003): 9.

${ }^{67}$ Ibid.

${ }^{68}$ Ibid.

${ }^{69}$ Ibid.

${ }^{70}$ Ibid.
} 
The last component of Internet communication that deserves attention is accessibility. Although, as previously stated, 99 percent of public schools are connected; there is the remaining one percent that is not connected; not to mention the many international areas that have not obtained such technology yet. It is simply not feasible to include the non-users in a study of Internet communicators. With further study, the author will attempt to reveal that the communicators who are using cyberspace as their playing field are effectively and coherently conversing. An additional concept to be monitored is the amount of language deconstruction that occurs in an instant message conversation.

\section{Hypotheses}

H1: The samples of instant messaging conversations in a professional setting will be more formal in nature.

H2: The samples of instant messaging conversations in a personal setting will have more language deconstruction such as abbreviations, no capital letters or punctuation, improper grammar, incomplete sentences, spelling errors, and a greater use of emoticons than the business/professional related conversations.

H3: The samples of instant messaging conversations in the professional setting will be based on work-related issues such as business meetings, projects, etc., rather than small talk. Small talk occurs in the workplace when work is no longer being discussed and co-workers start to talk about other issues such as gossip about other co-workers, bad-mouthing a boss, or making lunch plans.

\footnotetext{
${ }^{71}$ McQuillen, Education, 618.
} 
H4: The samples of instant messaging conversations in the personal realm will include more small talk and gossip than those in the professional setting. Examples of small talk/gossip include evening plans, a current love interest, or simply catching up with a friend.

H5: Because of the frequent use of the Internet as a communications tool, today's educators will see a decline in their students' writing skills. For example, grammar-like errors such as abbreviations, punctuations errors, and basic sentence structure mistakes will be more prevalent in the students' writing currently than in years past.

\section{Methods}

To comprehend the analysis of this instant message content analysis, operational definitions must be explained and applied to the sample conversations. The operational definitions beginning with the categories, and then followed by subcategories and types are:

Professional Conversations: Communication that takes place in a business setting.

Personal Conversations: Communication that takes place in a personal/home-like setting.

Social Communication: This can be associated with both professional and personal communication. Social communication is less formal, and more small talk/gossipy in content.

Scholarly Communication: This can be associated with both professional and personal communication. Scholarly communication is more formal than social, and is more work-related in content. 
Intimate Communication: This type should be associated more in the personal communication category; however it is possible that some intimate exchanges may surface in a professional environment. Intimate conversation is mostly informal and can be sexual, an announcement of an attraction, or discussion of a romantic relationship. Highly Deconstructed Language (HDL): This communication type includes abbreviations, little or no punctuation, little or no capital letters. This type will also exhibit poor grammar, spelling, and syntax. The use of emoticons may be present as well.

Moderately Deconstructed Language (MDL): This communication type is more organized than the highly deconstructed in that it has more punctuation, fewer abbreviations, some capitalized proper names, places, etc. The moderately deconstructed type will use better grammar, few spelling errors and more coherent syntax. Emoticons should be less present in this form. Emoticons are normally used on an informal level therefore they should not be used as frequently as in HDL.

Non-deconstructed Language (NDL): This communication type is the most organized of the three variables. It has a essay-like form because it uses capital letters, punctuation, proper grammar, few spelling errors (some errors reserved for typos), and complete sentences. Few, possibly no, emoticons will be used.

Table 1.1 illustrates the way the variables are broken down for coding purposes. 

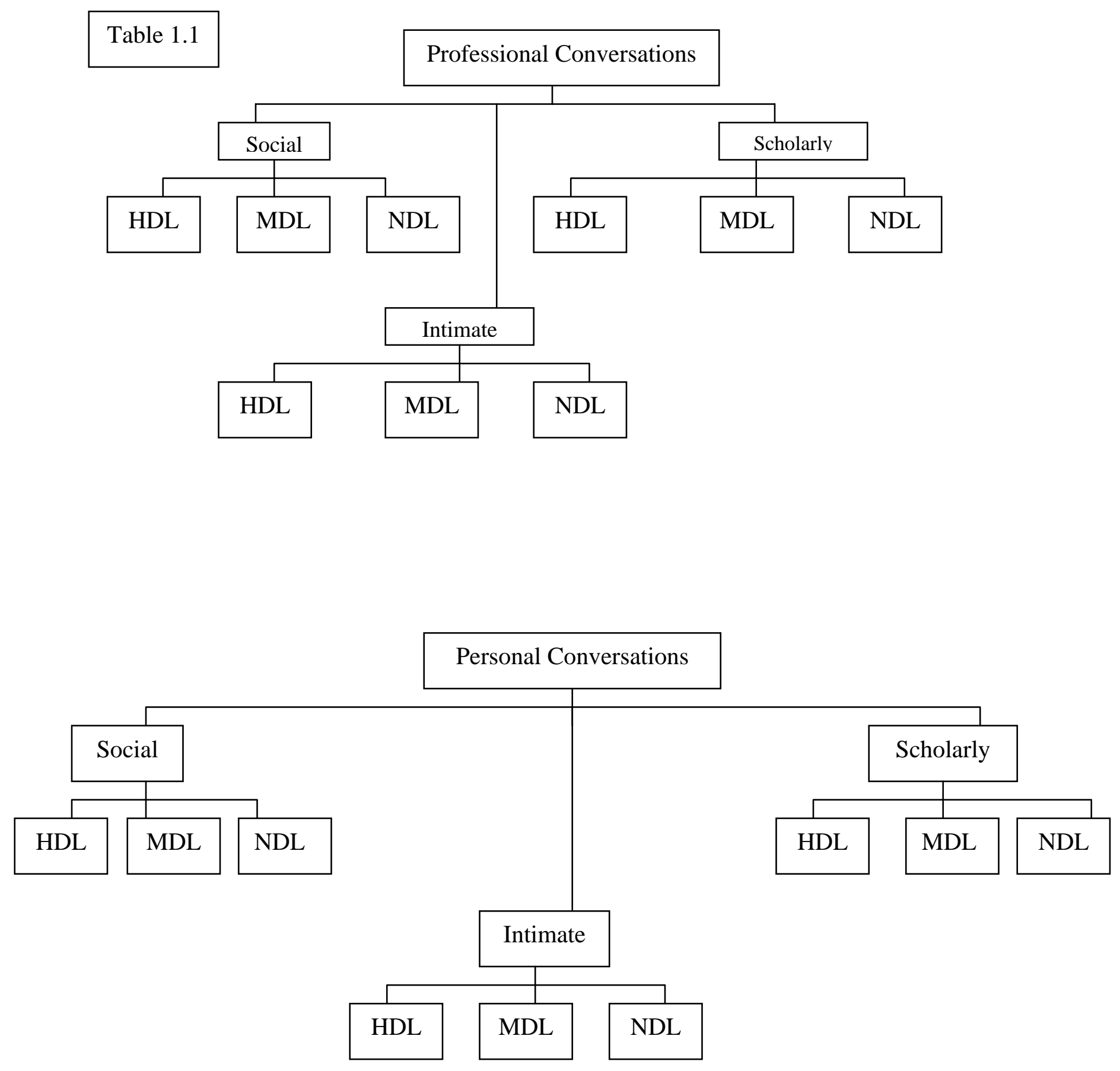

The purpose of the study is to examine the differences between instant message conversations that take place in a professional setting and those that take place in a personal setting. The comparison also will examine the subject matter and language 
deconstruction of the conversations. The unit of analysis of this study is 55 individual instant messages gathered starting in spring 2004. To obtain sample conversations, the researcher requested copies of conversations from willing online communicators. Each exchange involved two speakers, who will be coded separately. The conversations were donated to the researcher by willing AOL instant message users; and, as a result, the material is a convenience sample. The names in the raw data samples have been changed to give the speakers anonymity. The first step of coding an instant message conversation is to determine whether the conversation took place in a professional or personal setting. However, the number of professional and personal exchanges is not evenly dispersed. Most office conversations take place via the telephone or Email. Many businesses have not adopted the practice of instant messaging for professional use. [See Appendix 2 for Sample Code Sheet.] The sources of the conversations were able to inform the coder of where they were located during the communication, such as in the workplace or in a more unofficial setting, such as in front of their home computer. Once the location is determined, the entire conversation must be examined and categorized as formal or informal. A formal conversation is "all business." The author suspects that scholarly conversations in the professional setting will be formal in that there should be no interruptions in the flow by small talk or fluffy conversation that is not work-related. Informal conversations are lighter in conversational content, and are expected to be more prevalent in the personal setting. If the conversation has no existing formal or informal qualities, it can be classified as neither. After the conversation style has been determined by the coder, the conversation is further broken down into subcategories. The existing subcategories of the personal setting are social communication, intimate communication, 
and scholarly communication. The subcategories for professional conversations are social, intimate, and scholarly as well. After the content of the instant messages is analyzed for the subcategories, the mechanics must be examined for the types. The types used in both professional and personal categories are highly deconstructed language (HDL), moderately deconstructed language (MDL), and non-deconstructed language (NDL). In order to get the most accurate information possible, each speaker of the conversation is coded separately. For example, "Guest 1" may use a highly deconstructive type and "Guest 2" may be totally non-deconstructive. Therefore, each speaker must be coded separately so that the results are as accurate as possible.

As previously stated, when filling in a code sheet the coder must examine both content and mechanics of the conversations. After the location has been documented, the subcategory of each conversation must be identified. The theme of the conversation is important in determining the proper subcategory. For example a social theme may be an inquiry on where a co-worker is eating lunch.

The next concern of the coding is the language deconstruction that takes place. The type can be identified by examining seven elements of communication. These seven are use of abbreviations, capital letters, punctuation, proper grammar, complete sentences, spelling errors, and emoticons. If all of the elements are properly executed then the type of the exchange is non-deconstructive. For example, a non-deconstructive communicator’s style may appear like:

Are you going to the concert? Before you go call me and we can meet outside the Blue Gate. I will be leaving at 6:30. See you there! 
If the majority, four or more, are executed properly, then the conversation is classified as moderately deconstructed. The same quotation in moderate mode would appear different in composition but not in meaning:

are you going to the concert? I will be leaving at 630 . before you go call me and meet me outside the blue gate. see ya their! :)

Moderately deconstructed, depending on the communicator, may not capitalize proper names or the beginning of a sentence, but he or she may punctuate properly; and vice versa. Minor spelling errors and typos are acceptable for MDL as well. Some moderately deconstructive speakers will use emoticons.

Finally, if the majority, four or more, are not properly executed, the communication is clearly highly deconstructed. For example, the same quotation applied to an HDL communicator may look like a new language to non-IM users:

R u goin to the concert...i will be leavin @ 630, b4 u go, call me and meet at blu gate. c ya! :) :-;

HDL is synonymous with phrases like "internet shorthand" and "im language." Highly deconstructive chatters may leave out smaller words such as "the,” "and,” etc. The use of capitalization and punctuation is usually sporadic and inconsistent. As stated before, IM users have their own language and new abbreviations and symbols are being used daily.

A properly executed conversation uses capital letters and punctuation where appropriate. Complete thoughts are also expressed in complete sentences; proper grammar is implemented, and no spelling errors or abbreviations are displayed. Emoticons are not a critical part of the language deconstruction but still exist in the coding process. Examining the use of emoticons in an instant message conversation is 
significant in showing that a symbol can convey the same message that a nonverbal cue does in face-to-face communication. Emoticons are also necessary to this study in that they often encapsulate a feeling of informality and run the risk of stripping a professional conversation of its formal tone.

A second research study was done to tackle Hypothesis five. Again, the question is, Are today's students allowing their “internet language” to trickle into their academic submissions for a school newspaper, graded essay, etc? To support the idea that writing skills are being affected by instant messaging, the researcher had to produce a collection of questions for secondary and post-secondary educators. [See Appendix 1 for Interview Guide.] This qualitative analysis consists of in-depth interviews with college and high school journalism professors. The author did a nationwide search and interviewed 10 urban high school teachers, 10 rural high school teachers, 10 urban college professors, and 10 rural college professors. The interviews were conducted in order to examine the presently neglected subject of language deconstruction. A website entitled myhighschooljournalism.org provided hundreds of contacts to high school newspaper advisors and journalism teachers for all 50 states. The research sent 162 emails to high schools across the nation. Many of the email addresses were out of service or not working; however, some of them had high school educators with strong opinions on the receiving end.

The author emailed the potential subject an interview guide with a brief preface to introduce the researcher, explain the purpose of the study, and request the participation of the receiver:

My name is Lara Eller, and I am a journalism graduate student at West Virginia University. For my thesis research I am interviewing high school [college] 
journalism instructors on the performance of their students in relation to writing skills and Internet communication. Please consider answering the short list of questions listed below. Your participation would be greatly appreciated. You may forward or reply to this message with your responses included. Thank you for your time, Lara L. Eller $<><$

Then, the educators of introductory journalism courses were questioned on the success of their students on whether Internet shorthand has been habitually included in a paper submitted for grading. The researcher received responses from high school and college instructors all over the United States. [Sample Completed Interviews can be reviewed in Appendices 3-6.]

Once the questionnaires were returned, the schools were divided into rural and urban categories. Rural schools typically had a lower enrollment, 1,500 students or less, with the exception of one rural Texas high school. Also, the rural schools were located in more of a small town setting such as farmlands and no major highways. On the other hand, the urban schools were located in very populated areas with big industries and major highways. In order to generate impressions about the school's writing program, the researcher established demographics for each school such as dominate ethnicity in the school, whether it was public or private, and the actual population of the institution. By applying such demographics it is possible that for example, private schools will have a higher computer literacy figure, or schools on Indian reservations will have fewer grammar errors in their work than predominantly white schools. Applying demographics to each institution is an asset to the research in that the distinctions within the school can separate them from other schools and possibly allude to whether that distinction is influential on the results of the study. 


\section{Results and Discussion}

Once the sample conversations were coded, the researcher noticed a trend. IM users, for the most part, seem to spend their time communicating on an informal level in both the office and at home. They avoid "heavy" in-depth conversations, and most exchanges are brief. Small talk is the main theme of conversation. Of course, in the business setting some work was discussed; but with the small sample size of professional conversations, it is erroneous to generalize. Even so, the normal "hey, how are ya" idletype chatter was displayed in both categories. The results of this convenience sample are as follows: The professional setting sample contained 11 conversations. The personal setting sample contained 46 conversations. Tables 1.2 and 1.3 show the results and figures of the 55 conversations after the coding process was completed. Although there are 55 conversations, each speaker is coded separately Because of the different style of conversation that is unique to each guest. Table 1.2 examines the 11 professional conversations; however 22 guests are checked for language deconstruction. Table 1.3 examines the 46 personal conversations, and 92 guests are checked for language deconstruction. Two guests are presented in each exchange; therefore, the number in the conversation is doubled when checking for language deconstruction.

Table 1.2

\begin{tabular}{|c|c|c|c|}
\hline Subcategory & HDL & MDL & NDL \\
\hline Social (5) & 0 & 2 & 8 \\
\hline Scholarly (6) & 4 & 2 & 6 \\
\hline Intimate (0) & 0 & 0 & 0 \\
\hline
\end{tabular}


Table 1.3

\begin{tabular}{|c|c|c|c|}
\hline Subcategory & HDL & MDL & NDL \\
\hline Social (40) & 62 & 17 & 1 \\
\hline Scholarly (2) & 4 & 0 & 0 \\
\hline Intimate(4) & $\mathbf{8}$ & 0 & 0 \\
\hline
\end{tabular}

The hypotheses written prior to the coding may now be applied to the results of the content analysis. The researcher had certain ideas in mind to explore before the coding process took place and thus the hypotheses were formed. The first hypothesis stated that the instant message conversations in a professional setting would be more formal in nature. Although only two of 11 professional conversations were formal, zero of the 46 personal conversations were formal. In this study, hypothesis one is supported even if the results are rather marginal.

Hypothesis number two stands behind the idea that personal conversations will have more language deconstruction than professional/business-related conversations. Based on the numbers on the chart this hypothesis is supported. Seventy-four of the 88 speakers examined were highly deconstructive; 17 were moderately deconstructed, which leaves only one in the non-deconstructed type column. On the other hand, the professional conversations had four highly deconstructed; four moderate; and the remaining 14, non-deconstructed.

The third hypothesis predicts that the professionally located conversations would discuss more work-related concepts rather than idle chatter. Six of 11 conversations were 
primarily work-related. Oftentimes professional conversations can have both social and intellectual topics within them. However, there is usually a primary focus in the conversation. For example, one conversation addressed issues of work and lunch in the same conversation. However, one topic was the dominating subject in the conversation and that is what determined whether the conversation was intellectually based or not. The remaining five conversations that were not focused on business were inquiries on lunch plans and casual gossip about co-workers. When these results are applied to hypothesis three, it is not supported.

The fourth hypothesis can be more clearly explained if the results were presented in percentages. It states that personal instant message exchanges will include more small talk, gossip, etc. than those in a professional setting. Because only 11 professional conversations were obtained and 55 personal conversations were gathered, the comparison is not a level playing field. When the categories were averaged, 86.9 percent of personal conversations were centered on small talk; whereas in the professional realm 45.4 percent were primarily small talk. Many business fields use inter-office phones, or emails instead of IM to communicate with their co-workers. Again, as in hypothesis one, the separation is not very large; but a difference does exist. With a small and uneven sampling group, it is simply not feasible to make a generalization for all professional instant messaging. However, this sample suggests that professionally located conversations, although more scholarly-centered than personal, are not as topically scholarly as the researcher assumed.

Instant messaging is a result of interaction with the technology of today's society. Whether or not it is a sufficient substitute of communication has yet to be established. 
Out of all 55 coded conversations, not one single topic appeared to be misunderstood by either speaker involved in the conversation. The following example shows a complete understanding between a highly deconstructive communicator and a non-deconstructive communicator. Although they manipulate the language differently, they are still able to comprehend the message the other is trying to express:

Guest 19 (10:24:47 PM): I'm so anal I insist on having my IM's typed correctly.

Guest 20 (10:24:56 PM): realy?

Guest 20 (10:24:57 PM): lol

Guest 19 (10:25:04 PM): I think it is good practice for writing quickly.

Guest 20 (10:25:11 PM): true

Guest 19 (10:25:20 PM): Typing may have been the most useful class I ever took.

Guest 20(10:25:23 PM): i sucks when i have to write formal papers

Guest 20 (10:25:35 PM): i type u $r$ for you are

Guest 19 (10:26:20 PM): The only way to get better at it is to DO it. Try typing your IM's correctly for practice. Internet slang is ruining our ability to spell and write well.

Guest 20 (10:27:00 PM): very true i have a friend those thesis in on that

Guest 19 (10:27:08 PM): Spell check is bad too. For example, you could misuse the word "to" for "too" and spell check wouldn't care. As Gallagher says, we need "Intelligence Checkers".

Guest 19 (10:27:27 PM): Your friend is brilliant. A+

The results of the qualitative study were more in-depth because there were 40 interviews of different schools with different agendas and characteristics. On the high school side some journalism instructors (mostly school newspaper advisors) were split down the middle on the topic of the Internet. Some felt it was a terrific research tool while others thought it was a writing and creativity killer. Some teachers even went as far to say that the Internet was basically an invitation to plagiarize. The question that opened the Internet good or bad debate was: "Do you believe the rise of the Internet has affected writing skills? Explain.” On the positive side, one urban high school teacher in Missouri said, "Information is more readily available and found quickly...."72 However, the response does not address the effects that computer-mediated communication has had on writing skills, only that the Internet is a great research device. A rural Mississippi

${ }^{72}$ High School Teacher, interviewed by Lara Eller, Chesterfield, Missouri, April 2005. 
journalism instructor believes that there are good and bad points to the success of the Internet and says she notices that the "students are writing less formal papers, but students are less afraid of writing [due to the Internet, spell check, etc.]"73 The positive comments on the topic of the Internet dealt more with the wealth of information that can be accessed rather than the affects it has on writing skills. For example, one of the most positive comments related to the question of Internet use in writing classes came from a rural Texas teacher, "With a few of the students, it gives them access to things they would [otherwise] never see or read...”74 The ethnicity break down in this school was 66\% Hispanic and 33\% White. In a somewhat culturally diverse (65\%white, 29\% Asian/Pacific Islander) urban school in New Jersey, the educator sums up the interview by saying “the world is changing, maybe communication doesn't need to be so formal (as in the way i responded to this email). ${ }^{75}$ Another teacher referred to the Internet slang as "approved fragmented writing."76 This alludes to the possibility that the Internet slang that is creeping into student writing is acceptable composition.

However, for as many praises for the Internet, there were twice as many criticisms of it. A Rhode Island senior English and mixed grade-level journalism teacher says she has to "warn the kids on day one that when they write for me, they are not "im-ing" me. It seems as though that 'shorthand' has woven its way into their writing and speech.",77 Most of the schools (high school more than college), although very diverse in location,

\footnotetext{
${ }^{73}$ High School Teacher, interviewed by Lara Eller, Picayune, Mississippi, April 2005.

${ }^{74}$ High School Teacher, interviewed by Lara Eller, Sabinal Texas, April 2005.

75 All grammatical "mistakes" are how they appeared in the actual email.

${ }^{76}$ High School Teacher, interviewed by Lara Eller, Pampa, Texas, April 2005.

${ }^{77}$ High School Teacher, interviewed by Lara Eller, Cumberland Rhode Island, April 2005.
} 
ethnicity, and population seem to have the problem of separating their formal writing with their IM writing. These impressions would appear to support hypothesis five in that a large part of student writing has suffered because of the Internet being used as a communications tool.

Colleges appeared to encounter some of the same problems, but on a smaller scale. Many college students in journalism classes are planning to be journalism majors and typically have better writing skills. Therefore, they are better at separating Internet slang from acceptable and grammatically correct writing. One California journalism professor stated: “Generally speaking, I’d say the writing skills of my students vary from excellent to below average. Since my students are journalism majors, I would expect them to have better self-editing skills, but many do not possess such skills upon arrival to the University.” He also said the many of the students entering college today are coming in with lower writing skills. He does not attribute this breakdown to the Internet but to failure to re-edit their work and lack of attention to detail. ${ }^{78}$ A professor at Belmont School of Journalism in Tennessee commented that students used to be more creative. She says “Now, thanks to the Internet and sensationalism, they don’t write with the depth and clarity of students past." ${ }^{79}$ Again, the professor did not mention an excessive amount of language deconstruction and IM shorthand showing up in their students' like the high school instructors noted. Most of the colleges across the U. S. were more concerned with the Internet encouraging “cut and paste” and plagiarism. However, one high school journalism teacher, also an adjunct at a local state university claimed, "Students in [his]

\footnotetext{
${ }^{78}$ College Instructor, interviewed by Lara Eller, Los Angeles, California, April 2005.

79 College Instructor, interviewed by Lara Eller, Nashville Tennessee, April 2005.
} 
class seem a lot worse than the high school students!"80 Of course there will be different opinions from separate individuals and institutions; but in large part, the language deconstruction reported in the high school interviews was not as prevalent in the college writing. The impression is most college students are not using Internet language in their composition.

With only 20 interviews from college faculty and 20 interviews from high school instructors, no generalizations can be made. Countless institutions were not even contacted. Therefore, with such a small sample size, the research can only make an inference about the information submitted.

\section{Conclusion}

Of course, there are limitations in every study. The limitations to the content analysis study are the sample size and the fact that it is a convenience sample. Because the professional sample size is smaller than the personal sample, the figures do not match. One option for future research would be to examine the education level of each online communicator. An additional interesting concept to explore with a sample of this nature would be each speaker’s specific characteristics. Perhaps demographics such as gender and race relate to an individual's conversational style.

In the qualitative study the sample size was small. With only 40 interviews the questionnaire, unfortunately, did not reach all 50 states. On the positive side, in both college and high school responses, trends did exist. For example, more than half of the high school educators reported Internet language in their students' writing. College

\footnotetext{
80 Journalism Instructor, interviewed by Lara Eller, April 2005. The instructor, did not provide the researcher with the name of the school, therefore no demographics were established for said institution.
} 
professors did not mention as much slang in compositions. The primary cited concerns of interviewed college educators were plagiarism and lazy editing.

This author observed that not all communicators use complete sentences when they "talk" on IM. However, while the language of one speaker may be nondeconstructive and the language of another may be highly deconstructive, both people are still able to communicate effectively. Therefore, the argument that individuals who manipulate the language must first know how to use the language to manipulate it is compelling.

This researcher's coding samples for instant message conversations introduce a new concept. The study contributes new data about instant messengers. The neglected topic of language deconstruction has now been studied through an extensive content analysis and a qualitative series of in-depth interviews.

Recently published reports state that instant messaging is so popular that 74 percent of teens who use the Internet admit to using instant messaging. Thirty-five percent claim to use it everyday. ${ }^{81}$ Another article declared that America Online has 195 million people who use its instant messaging service, ${ }^{82}$ and AOL is not the only instant message provider available. If instant messaging is not a suitable form of communication, then why does it have such a substantial following? Recently published information is extremely convincing that instant message communication is a functional, comprehensive substitute for face-to-face exchanges.

\footnotetext{
${ }^{81}$ www.columbia.edu/ kew2005/full-report.htm. Accessed: April 14, 2004.

${ }^{82}$ http://www.computeruser.com/clickit/printout/news/324576720006499840.htm. Accessed: April 14, 2004
} 
Sources included in this document may be revisited to further explore the theory of technological determinism, the content analysis results, and the qualitative studies' implications. Information in the literature review can provide additional support for the idea that instant messaging could possibly be a sufficient substitute for interpersonal and written communication. 


\section{Bibliography}

Chesebro, James W., and Donald G. Bonsall. Computer Mediated Communication: Human Relationships in a Computerized World. Tuscaloosa: The University of Alabama Press, 1989.

Etzioni, Maitai, and Oren Etzioni. "Face-to-Face and Computer-Mediated Communities: A Comparative Analysis.” Information Society 15 (October- December 1999): 241-48.

Gackenbach, Jayne, ed. Psychology and the Internet: Intrapersonal, Interpersonal, and Transpersonal Implications. San Diego: Academic Press, 1998.

Jones, Steven G., ed. Virtual Culture: Identity and Communication in Cybersociety. London: Sage Publications, 1997.

Lewis, Cynthia, and Bettina Fabos. "But Will it Work in the Heartland? A Response and Illustration.” Journal of Adolescent and Adult Literacy 43 (February 2000): $462-67$.

Lowery, Shearon A., and Melvin L. DeFleur. Milestones in Mass Communication Research: Media Effects. New York: Longman Publishers USA, 1995.

McQuillen, Jeffrey. "The Influence of Technology on the Initiation of Interpersonal Relationships.” Education 123 (Spring 2003): 616-21.

Poindexter, Paula M., and Maxwell E. McCombs. Research in Mass Communication: A Practical Guide. Boston: Bedford/St. Martin's, 2000.

Redmond, Mark V. Interpersonal Communication: Readings in Theory and Research. Fort Worth: Harcourt Brace College Publishers, 1995.

Wallace, Patricia. The Psychology of the Internet. Cambridge: Cambridge University Press, 1999.

Warschauer, Mark. "Demystifying the Digital Divide.” Scientific American 289 (August 2003): 42-6.

Wolak, Janis, Kimberly J. Mitchell, and David Finkelhor. "Close Online Relationships in a National Sample of Adolescents.” Adolescence 37 (Fall 2002): 44150. 
Websites:

http://www.arapaho.nsuok.edu/\%7Evinevard/Research/Mass_Culture_Theories.htm. Accessed: October 21, 2003.

http://www.cartoon.ecn.purdue.edu/ birkhaus/H515pt1a.html. Accessed: September 30, 2003.

http://www.cnn.com/2003/EDUCATION/10/29/students.computers.ap/index.html. Accessed: November 10, 2003.

http://www.cnn.com./2003/TECH/internet/09/16/using.IM.reut.index.html. Accessed: September 16, 2003.

http://www.columbia.edu/ kew2005-report.htm. Accessed: April 14, 2004.

http://www.computeruser.come/clickit/printout/news/32457620000649984.htm. Accessed: April 14, 2004.

http://www.leaderu.com/orgs/probe/docs/mcluhan.html. Accessed: May 2005.

www.myhighschooljournalism.org. Accessed: April 2005.

www.census.gov/population/urpop0090.txt. Accessed: April 2005

Interviews:

High School Teacher, interviewed by Lara Eller, Chesterfield, Missouri, April 2005.

High School Teacher, interviewed by Lara Eller, Sabinal, Texas, April 2005.

College Instructor, interviewed by Lara Eller, Los Angeles, California, April 2005.

High School Teacher, interviewed by Lara Eller, Picayune, Mississippi, April 2005.

High School Teacher, interviewed by Lara Eller, Pampa, Texas, April 2005.

Journalism Instructor, interviewed by Lara Eller, April 2005.

High School Teacher, interviewed by Lara Eller, Cumberland, Rhode Island, April 2005.

College Instructor, interviewed by Lara Eller, Nashville, Tennessee, April 2005. 


\section{Appendix 1}

\section{Interview Guide}

1. How long have you been teaching?

2. What age group do you teach (i.e., high school juniors, college freshman...)?

3. On a scale of 1 to 10 (one being the lowest and 10 being the highest), how computer literate would you say your students are?

4. Have you noticed any changes in your students' writing in recent years?

5. If so, what kind of changes?

6. Do you believe the rise of Internet communication has affected writing skills? If so, How?

7. How does writing in the past compare to what you are seeing today?

8. Do you spend more time teaching grammar, spelling, and punctuation than in years past?

9. Do you notice any excessive composition errors such as unnecessary abbreviations, misspelled words, and/or lack of punctuation in your students' work?

10. If you do, why do you think these errors occur?

11. Do you have any additional comments regarding the performance of your classes? 


\section{Appendix 2}

Code Sheet

Lara L. Eller

Conversation Categories: Personal (V1) Professional (V2)

Conversation Subcategories: $\quad$ Social (V3) Scholarly (V4) Intimate (V5)

Conversation Types: $\quad$ HDL (V6) MDL (V7) NDL (V8)

\section{Location of Conversation}

A. Category:

\section{Content Material}
A. Theme of Conversation:
B. Conversation Style:
Formal
Informal Neither
C. Subcategory:
D. Subcategory elements:

\section{Language Deconstruction Material}

\section{Guest}
A. Type:
B. Abbreviations: Yes No
C. Capital Letters: Yes No
D. Punctuation: Yes No
E. Proper Grammar: Yes No
F. Complete Sentences: Yes No
G. Use of Emoticons: Yes No
H. Spelling Errors: $\quad$ Yes No 


\section{Guest}
A. Type
B. Abbreviations: Yes No
C. Capital Letters: Yes No
D. Punctuation: Yes No
E. Proper Grammar: Yes No
F. Complete Sentences: Yes No
G. Use of Emoticons: Yes No
H. Spelling Errors: Yes No

\section{Additional Comments:}




\section{Appendix 3}

\section{Urban High School Interview (Iowa)}

From: leller@mix.wvu.edu [mailto:leller@mix.wvu.edu]

Sent: Mon 4/4/2005 6:30 PM

Subject: A letter to the editor

Comments/Questions?

My name is Lara Eller and I am a journalism graduate student at West Virginia

University. For my thesis research I am interviewing high school journalism instructors on the performance of their students in relation to writing skills and Internet communication. Please consider answering the short list of questions listed below. Your participation would be greatly appreciated. You may forward or reply to this message with your responses included. Thank you for your time, Lara L. Eller $<><$

Interview Questions

1. How long have you been teaching? 6 years

2. What age group do you teach (i.e., high school juniors, high school freshmen, etc...)? high school...including all four grades

3. On a scale of one to 10 (one being the lowest and 10 being the highest), how computer literate would you say your students are? 8

4. Have you noticed any changes in your students' writing in recent years? yes

5. If so, what kind of changes? The content of their writing is better. I think it's because they are exposed to better writing.

6. Do you believe the rise of the Internet has affected writing skills? Explain. Yes. I think they write better quality, but are lazy as far as spelling, grammar, etc., because they feel the computer will catch everything.

7. How does the writing of students in the past compare to what you are seeing today? They seem to write more compact, like a USA today style writing.

8. Do you spend more time teaching grammar, spelling, and punctuation than in years past? No.

9. Do you notice any excessive composition errors such as unnecessary abbreviations, misspelled words, and/or lack of punctuation in your students' work? Yes. They think "u" is fine for you..things like that. 
10. If you do, why do you think these errors occur? MSN, e-mail, etc.

11. Do you have any additional comments regarding the performance of your classes on this topic of Internet communication and writing skills? No 


\section{Appendix 4}

\section{Sample High School Interview (Pennsylvania)}

Interview Questions

$>$

$>1$. How long have you been teaching? 8 years

$>$

$>2$. What age group do you teach (i.e., high school juniors, high school freshmen, etc...)? high school -- all levels

$>$

$>$ 3. On a scale of one to 10 (one being the lowest and 10 being the highest), how computer literate would you say your students are? most: 7 or 8

$>$

$>4$. Have you noticed any changes in your students' writing in recent years? yes

$>$

$>$ 5. If so, what kind of changes? can't spell to save their lives -- rely on grammar check which is not always correct -- and they're generally much lazier because of the internet and technology in general $>$

$>6$. Do you believe the rise of the Internet has affected writing skills? Explain. see number 5 -- but also -- im language is killing things...

$>$

$>7$. How does the writing of students in the past compare to what you are seeing today? much better in the past

$>$

$>8$. Do you spend more time teaching grammar, spelling, and punctuation than in years past? no, but the lower grades should -- i'm talking basics -- if i ask a kid to pick the nouns or verbs out of a sentence, they have to think for a long time before being able to do it, if they're able to do it -- and i'm talking juniors and seniors $>$

$>9$. Do you notice any excessive composition errors such as unnecessary abbreviations, misspelled words, and/or lack of punctuation in your students' work? absolutely -- again, due to instant messages (but, as you can tell, i'm not a stickler on capitalization for informal things, either...

$>$

$>10$. If you do, why do you think these errors occur? instant messaging / general laziness / don't care...

$>$

$>11$. Do you have any additional comments regarding the performance of your classes on this topic of Internet communication and writing skills? no... 


\section{Appendix 5}

\section{Sample College Interview (California)}

1. How long have you been teaching?

I taught elementary school for eight years; I've been a fulltime faculty here for one year; before that I taught university level part-time for three years.

2. What age group do you teach (i.e., college juniors, freshmen, etc?)?

All levels . . .

3. On a scale of one to 10 (one being the lowest and 10 being the highest), how computer literate would you say your students are?

It's difficult to generalize, but on average I'd say 6 .

4. Have you noticed any changes in your students? writing in recent years?

Generally speaking, I'd say the writing skills of my students vary from excellent to below average. SInce my students are journalism majors, I would expect them to have better selfediting skills, but many do not possess such skills upon arrival to the university ...

5. If so, what kind of changes?

6. Do you believe the rise of the Internet has affected writing skills? Explain.

I would say that the internet has affected the students' research and writing skills because it must be very tempting for them to take advantage of a "cut and paste" mentality. I'm not saying that plagiarism is a major issue in my classes, but I know it is a growing concern in general.

7. How does the writing of students in the past compare to what you are seeing today?

Comparing with my years as an undergraduate student (in the 1980 's), I think students are coming into college with lower 
writing skills these days. I'm referring to students who have spent their lives in the public schools here in the Los Angeles area. Of course there are exceptions to this.

8. Do you spend more time teaching grammar, spelling, and punctuation than in years past?

Not applicable (though I do proofread my students' work and make corrections)

9. Do you notice any excessive composition errors such as unnecessary abbreviations, misspelled words, and/or lack of punctuation in your students? work?

I wouldn't say excessive, but more than there should be at this level.

10. If you do, why do you think these errors occur?

Lack of attention to detail (not bothering to rewrite).

11. Do you have any additional comments regarding the performance of your classes on this topic of Internet communication and writing skills?

No, but it is an important topic that needs close attention. 


\section{Appendix 6}

\section{Sample College Interview (Tennessee)}

Lara Leigh Eller wrote:

$>$ My name is Lara Eller and I am a journalism graduate student at West $>$ Virginia University. For my thesis research I am interviewing college $>$ journalism instructors on the performance of their students in relation $>$ to writing skills and Internet communication. Please consider $>$ answering the short list of questions listed below. Your participation $>$ would be greatly appreciated. You may forward or reply to this message $>$ with your responses included. Thank you for your time, Lara L. Eller $<><$ $>$

$>$ Interview Questions

$>$

$>1$. How long have you been teaching?

Ten years

$>2$. What age group do you teach (i.e., college juniors, freshmen, etc\&)? College Freshman, sophomores and juniors

$>3$. On a scale of one to 10 (one being the lowest and 10 being the >highest), how computer literate would you say your students are? 10

$>4$. Have you noticed any changes in your students writing in recent $>$ years? Yes.

$>$

$>5$. If so, what kind of changes?

They don't seem to understand the information about which they are writing. Subjectivity is overpowering objectivity. They also have trouble with attribution. Grammar has definitely declined as well.

$>6$. Do you believe the rise of the Internet has affected writing skills? $>$ Explain.

Indeed, the Internet has provided a crutch for many students. Instead of thinking, some are surfing. They would rather have information given to them instead of learning different processes and skills on their own. The Internet has affected their attitudes and demand for immediate information. They seem to believe that they should learn as quickly as a microwavce prepares their meals.

$>7$. How does the writing of students in the past compare to what you are $>$ seeing today? 
In many ways, students used to be more creative. Now, they seem to engage in cookie cutter journalism which unfortunately is also happening in mainstream newsrooms. Before, they understood why the inverted pyramid was important or extra substantive information for a broadcast news report. Now, thanks to the Internet and sensationalism, they don't write with the depth and clarity of students past.

$>8$. Do you spend more time teaching grammar, spelling, and punctuation $>$ than in years past?

Yes, we do. One class is currently reading Eats, Shoots and Leaves.

$>9$. Do you notice any excessive composition errors such as unnecessary $>$ abbreviations, misspelled words, and/or lack of punctuation in your $>$ students work?

Not an exorbitant amount. The students, at the least will use spell check.

$>10$. If you do, why do you think these errors occur?

They are used to machines computing information, from calculators to computers. It is a very dangerous scenario.

$>11$. Do you have any additional comments regarding the performance of $>$ your classes on this topic of Internet communication and writing skills? Overall, our students are good writers. They value the end result. It is just matter of getting them excited about and committed to the process. 